\title{
Ações intersetoriais para promoção da saúde na Estratégia Saúde da Família: experiências, desafios e possibilidades
}

\author{
Intersectorial actions for health promotion in Family Health Strategy: experiences, challenges, and possibilities \\ Acciones intersectoriales para la promoción de salud en la Estretégia Salud de la Familia: experiencias, desafíos y \\ posibilidades
}

\author{
Kênia Lara Silva', Andreza Trevenzoli Rodrigues" \\ 'Universidade Federal de Minas Gerais. Escola de Enfermagem. Belo Horizonte, MG \\ "Pontifícia Universidade Católica de Minas Gerais. Escola de Enfermagem. Belo Horizonte, MG
}

Submissão: 29/07/2009

Aprovação: 10/07/2010

\section{RESUMO}

Estudo Qualitativo cujo objetivo foi analisar praticas intersetoriais para promoção da saúde na Estratégia Saúde da Família, identificando as experiências, os fatores facilitadores e restritivos ao processo de construção de parcerias. Os sujeitos foram o gerente, agente comunitário de saúde e informantes-chave de equipamentos sociais da área de abrangência de um Centro de Saúde localizado em Belo Horizonte/Minas Gerais. Os resultados permitem evidenciar a existência de uma ampla rede social. Entretanto, as práticas intersetoriais para promoção da saúde ainda são incipientes. Apresenta-se como desafio para a intersetorialidade a criação de espaços comunicativos Que possibilitem a resolução de problemas complexos. Conclui-se Que intersetorialidade é uma estratégia inovadora ainda em construção, cujos caminhos estão sendo desvendados.

Descritores: Promoção da Saúde; Programa Saúde da Família; Ação Intersetorial.

\section{ABSTRACT}

Qualitative study with the purpose of analyzing intersectorial actions for health promotion in the context of the Family Health Strategy, identifying experiences, facilitating and restricting factors to the process of building partnerships. Subjects were health managers and informers from social equipment in the territory covered by a local health service in Belo Horizonte/Minas Gerais, Brazil. The results indicate the existence of a wide social network. However, intersectorial health promoting actions are still incipient. Intersectorial actions are faced with the challenge of creating communication spaces that allow the resolution of complex problems. It is concluded that intersectorial actions constitute an innovative strategy which is still under construction, and the paths of which are still being unraveled. Key words: Health promotion; Family Health Program; Intersectorial action.

\section{RESUMEN}

Estudio cualitativo realizado con el objetivo de analizar prácticas intersectoriales para promover la salud en la Estrategia Salud de la Familia identificando las experiencias y los factores facilitadores y restrictivos al proceso de construcción de alianzas. Los sujetos eran profesionales de salud e informantes clave de equipos sociales del área de alcance de un servicio local de salud situado en la ciudad de Belo Horizonte, Estado de Minas Gerais. Los resultados permiten detectar la existencia de una amplia red social; sin embargo, las prácticas intersectoriales para promover la salud todavía son incipientes. Para la intersectorialidad representa un reto crear espacios comunicativos Que permitan solucionar problemas complejos.Se concluye que la intersectorialidad es una estrategia novedosa, en construcción, con caminos Que ahora se están abriendo.

Descriptores: Promoción de la salud; Programa Salud de la Familia; Acción intersectorial. 


\section{INTRODUÇÂO}

Este estudo analisa as praticas intersetoriais para promoção da saúde na Estratégia Saúde da Família (ESF), identificando as experiências, bem como os fatores facilitadores e restritivos ao processo de construção de parcerias. Trata-se de um trabalho de conclusão de curso Que foi apresentado à Escola de Enfermagem da Pontifícia Universidade Católica de Minas Gerais núcleo Betim, para obtenção do título de graduação em Enfermagem.

Sabe-se Que a ESF propõe a prestação de uma assistência Que vá além do corpo biológico e Que seja capaz de alcançar os seres humanos em sua complexidade e integralidade ${ }^{(1)}$. E, para tal, devemse incluir ações Que ultrapassem os muros das unidades de saúde e atinja o contexto histórico, social, cultural, político e econômico dos indivíduos ou coletivos, no sentido de promover a saúde dos mesmos. A complexidade dessa proposta explicita a incapacidade do setor saúde de atuar isoladamente sendo necessária a criação de parcerias entre diferentes setores e segmentos sociais ${ }^{(2-3)}$. Portanto, a Política Nacional de Promoção da Saúde propõe Que as intervenções em saúde sejam ampliadas, tomando como objeto os problemas, necessidades, determinantes e condicionantes de saúde. Para tal, a organização da atenção e do cuidado deve criar mecanismos de mobilização e participação com os vários movimentos e grupos sociais, através da construção de parcerias ${ }^{(4)}$.

A intersetorialidade em saúde é compreendida neste estudo como uma relação reconhecida entre uma ou várias partes do setor saúde com uma ou várias partes de outro setor Que se tenha formado para atuar em um tema visando alcançar resultados de saúde de uma maneira mais efetiva, eficiente ou sustentável do Que poderia alcançar o setor saúde agindo por si só(5).

Partindo desse conceito, Wimmer e Figueiredo ${ }^{(6)}$ afirmam Que as micro e macroestratégias intersetoriais construídas em articulação por Estado e Sociedade Civil, contribuem significativamente para efetividade e eficiência das ações de saúde. Portanto, acredita-se Que tais articulações e arranjos podem ocorrer através da construção de parcerias entre diferentes setores e segmentos sociais como: educação, saúde, cultura, esporte, lazer, empresas privadas, organizações não-governamentais (ONGs), fundações, entidades religiosas, as três esferas de governo, organizações comunitárias, dentre outros.

Procurou-se, por meio desta pesQuisa, desvendar caminhos para o avanço das propostas de ações intersetoriais na ESF, através do compartilhamento de experiências, bem como da identificação de fatores facilitadores e restritivos à operacionalização da intersetorialidade em saúde. Ao disseminar o conhecimento resultante da pesQuisa pretende-se dar visibilidade às ações intersetoriais na ESF, no intuito de apoiar, estimular e fortalecer a prática. Acredita-se Que o referido conhecimento possa contribuir para a expansão das intervenções intersetoriais como estratégia de promoção da Qualidade de vida e, portanto, beneficiar à população, especialmente aos grupos vitimados por iniQuidades sociais.

\section{MÉTODO}

Trata-se de um estudo Qualitativo. Foi definido como cenário do estudo o serviço de atenção básica do município de Belo Horizonte. Dos 131 centros de saúde do município foi escolhido um, localizado na regional Barreiro, para a realização do trabalho de campo. O Centro de Saúde pesquisado conta com o trabalho de Quatro equipes de Saúde da Família, responsáveis por prestar assistência a uma população de aproximadamente 15.267 pessoas Que ocupa áreas de muito elevado, elevado e médio risco sócioeconômico-sanitário.

As técnicas utilizadas para a coleta de dados foram entrevista individual com roteiro semi-estruturado e observação. O período de coleta de dados estendeu-se de outubro de 2007 a janeiro de 2008. A primeira entrevista foi respondida pelo gerente do Centro de Saúde procurando-se identificar as experiências, desafios e possibilidades da intersetorialidade, de acordo com o ponto de vista do serviço de saúde local. Esta etapa do processo de coleta de dados também possibilitou dar início à construção da rede de parcerias existentes naQuele contexto, a partir da citação dos equipamentos sociais conhecidos pelo gerente, sendo esses equipamentos parceiros ou não do Centro de Saúde. Posteriormente, o mesmo instrumento de coleta foi utilizado para entrevistar um agente comunitário de saúde Que atua em uma das equipes da ESF.

A partir das informações identificadas nas primeiras entrevistas, iniciou-se a segunda etapa do processo de coleta de dados, a saber: entrevistas com os informantes chave dos equipamentos sociais citados pelo serviço de saúde. Essa etapa teve como objetivo dar continuidade à construção da rede de parcerias existentes ou possíveis de existir; além de permitir a análise do tipo de relação Que o serviço tem estabelecido com os setores e equipamentos sociais, bem como identificar os desafios e possibilidades da prática intersetorial, segundo a opinião desses informantes.

Os equipamentos sociais que participaram do estudo foram: Núcleo de Ação Social do bairro, uma creche vinculada à Prefeitura, duas escolas estaduais, um representante das três igrejas católicas e um representante do Núcleo Intersetorial Regional (NIR).

As Questões éticas foram observadas em todas as etapas da pesquisa, atendendo a resolução 196/96 do Conselho Nacional de Ética, sendo a pesquisa aprovada pelo Comitê de Ética em Pesquisa da Secretaria Municipal de Saúde de Belo Horizonte.

Todas as entrevistas foram gravadas em MP3, após a leitura do Termo de Consentimento Livre e Esclarecido e autorização por parte dos participantes.

Os dados empíricos foram analisados a partir de uma aproximação à Hermenêutica-Dialética. A escolha do referido caminho de pensamento foi feita por considerar as características do objeto deste estudo Que se relaciona simultaneamente com os processos sociais e com o processo saúde-doença. A HermenêuticaDialética possibilita uma reflexão compreensiva e crítica da análise da realidade social. Ela busca compreender os consensos e contradições do fenômeno estudado Que poderão ser explorados para a transformação de uma realidade historicamente estabelecida $^{(7)}$.

Para operacionalizar a compreensão dos dados a partir da Hermenêutica- Dialética, foram seguidas as etapas propostas por Minayo $^{(7)}$ : ordenação dos dados, classificação dos dados e análise final. A partir da leitura exaustiva dos discursos transcritos foram destacadas as idéias centrais contidas nos fragmentos de discurso dos sujeitos do estudo. Posteriormente, as idéia centrais foram agrupadas por similitude e desse agrupamento emergiram Quatro 
categorias empíricas: A intersetorialidade no contexto da ESF; O impacto das concepções dos profissionais no processo de construção da pratica intersetorial; Da fragmentação à integração: rompendo o limite do olhar setorial em busca da construção de um espaço comunicativo Que possibilite a resolução de problemas complexos e Desvendando caminhos para praticar a nova e promissora estratégia intersetorial.

Na etapa de análise final, os discursos e as observações sobre o trabalho de campo foram interpretados e confrontados com o referencial teórico consultado.

\section{RESULTADOS E DISCUSSÃO}

\section{Mapeamento das relações intersetoriais no cenário do estudo:} a rede como possibilidade de articulação?

A partir das entrevistas e das observações feitas no cenário do estudo foi possível mapear alguns setores, serviços e eQuipamentos sociais Que constituem uma rede complexa de parcerias existentes ou possíveis de existir. Para facilitar a visualização do todo a referida rede é apresentada no esquema demonstrado na Figura 1 .

O gerente do Centro de Saúde informou que conta com os seguintes parceiros: Escola Estadual JB, Creche Municipal, Grupo de Terceira Idade A, Igreja Católica A, NAS (Núcleo de Ação Social), NIR (Núcleo Intersetorial Regional). O agente comunitário de saúde entrevistado completou, informando que a Escola Estadual MN, a Sociedade São Vicente de Paulo e a Igreja Católica B também são parceiros.

De acordo com as entrevistas realizadas no Centro de Saúde, as escolas e a creche são parceiras no tocante ao desenvolvimento de algumas práticas de educação para saúde e empréstimo de área física para reuniões. O Informante da Escola JB também citou o Centro de Saúde como um de seus parceiros e assinalou outros três, a saber: Empresa de Telefonia, Secretaria de Educação e Indústria V.M.

A Secretaria de Educação é parceira da escola no desenvolvimento do "Projeto Abrindo Espaço". Este projeto oferece o espaço da escola, aos finais de semana, para que a comunidade possa praticar atividades de cultura, esporte e lazer. A Empresa de Telefonia oferece aos educandos cursos de música e dança. A empresa V.M., em parceria com a escola, desenvolve um projeto de educação sócio-ambiental, através de atividades como: espetáculos teatrais, oficinas, cursos de capacitação, etc.

Ao ser entrevistada, a diretora pedagógica informou Que a relação da Escola D.V. com o Centro de Saúde se restringe ao encaminhamento de alunos Que precisam ser atendidos por um profissional de saúde. A mesma diretora revelou Que a escola compartilha de parcerias com: Indústrias V.M e V.A, Empresa N.F, Centro Odontológico Privado e Igreja Católica C.

A indústria V.M. desenvolve na escola D.V o mesmo projeto sócio-ambiental já mencionado. Aos alunos Que gostam de esportes, a Indústria V.M oferece um projeto em Que o jovem participa de aulas de futebol, atividades de reforço escolar e recebe apoio psicossocial. A Empresa N.F disponibiliza mudas de árvores e ensina alunos do ensino fundamental a fazerem plantio e cultura de espécies vegetais. O Centro Odontológico pertence a uma iniciativa privada Que desenvolve ações preventivas na escola, além de oferecer tratamento dentário de baixo custo para os alunos. A parceria da escola com a igreja católica $\mathrm{C}$ refere-se ao encaminhamento de alunos para serem atendidos pelos profissionais de saúde Que prestam trabalho voluntário à comunidade através da paróQuia. Cabe ressaltar que a Escola D.V. também corresponde a um espaço de esporte e lazer, aberto aos finais de semana.

As Igrejas Católicas A e B são parceiras do Centro de Saúde somente no Que se refere ao empréstimo de área física para reuniões entre os trabalhadores e com a comunidade. Existem várias Igrejas Evangélicas na região, porém nenhuma delas foi citada como parceiras no desenvolvimento de trabalhos sociais e de promoção da Qualidade de vida.

A entrevista com o representante das Igrejas Católicas existentes na área de abrangência do Centro de Saúde revelou Que a Igreja C é um importante equipamento social da região, visto Que oferece à comunidade vários serviços prestados por voluntários. Entretanto, de acordo com as informações obtidas através das entrevistas, o Centro de Saúde não possui nenhum tipo de parceria com a referida instituição religiosa. Em um dos salões da Igreja $C$ funciona uma biblioteca Que foi fundada pela própria comunidade e atualmente é administrada pela prefeitura municipal. Nesta biblioteca são desenvolvidos projetos de cultura e lazer como, por exemplo, apresentações de Contadores de Estórias, peças teatrais educativas, etc. Em parceria com a mesma Igreja, profissionais voluntários prestam à comunidade atendimento médico, psicológico e fonoaudiológico. Além disso, outros voluntários ministram aulas de educação para jovens e adultos, aulas de instrumentos musicais e Yoga. Na igreja também há o Grupo de Terceira Idade B, no Qual são desenvolvidas, semanalmente, atividades físicas, educativas e de lazer.

Junto ao Grupo de Terceira Idade A, a gerente do Centro de Saúde informa Que, esporadicamente, são realizas palestras para orientação e prevenção das doenças crônico-degenerativas, além de serem feitos encaminhamentos de usuários do serviço de saúde para o grupo, Que se reúne semanalmente no salão da Igreja Católica $A$.

A parceria do Centro de Saúde com o Núcleo de Ação Social do bairro (NAS) ocorre através do apoio do serviço de saúde aos eventos Que o núcleo desenvolve na comunidade. O representante do NAS informou em sua entrevista Que a prefeitura é seu principal parceiro, visto Que ela tem oferecido apoio à maioria dos projetos sociais Que o núcleo propõe. Os comerciantes e a Indústria V.M também são referidos como parceiros do NAS por oferecerem recursos materiais para subsidiar os eventos e projetos Que são promovidos no bairro, dentre os Quais se destacam: um grupo de senhoras Que produzem artesanato como fonte de renda e um projeto Que dá oportunidade a jovens músicos, para Que possam apresentar seus trabalhos à comunidade.

A Sociedade São Vicente de Paulo é acionada pelo Centro de Saúde nas situações em Que há necessidade de suprir carências alimentares de famílias Que não estão em condições de se manterem.

O Núcleo Intersetorial Regional (NIR) foi citado como parceiro do Centro de Saúde por promover reuniões para discutir Questões relacionadas a intersetorialidade. O NIR foi criado no ano de 2004 , em Belo Horizonte, pela coordenação municipal do Programa Bolsa Família. Este núcleo tem como objetivo desenvolver um trabalho intersetorial envolvendo educação, saúde e assistência social com o objetivo de assistir às famílias Que descumprem as condicionalidade para o recebimento da Bolsa Família. 


\begin{tabular}{|l|l|l|l|l|}
\hline & Instituições Religiosas & $\rightarrow$ & Um setor ou equipamento social citou o outro como parceiro \\
\hline & Empresas/ Indústrias & $\leftrightarrow$ & A parceria é reconhecida pelos dois envolvidos \\
\hline & Escolas Estaduais & $\ldots \ldots$ & Não foi identificado nenhum tipo de parceria. \\
\hline
\end{tabular}

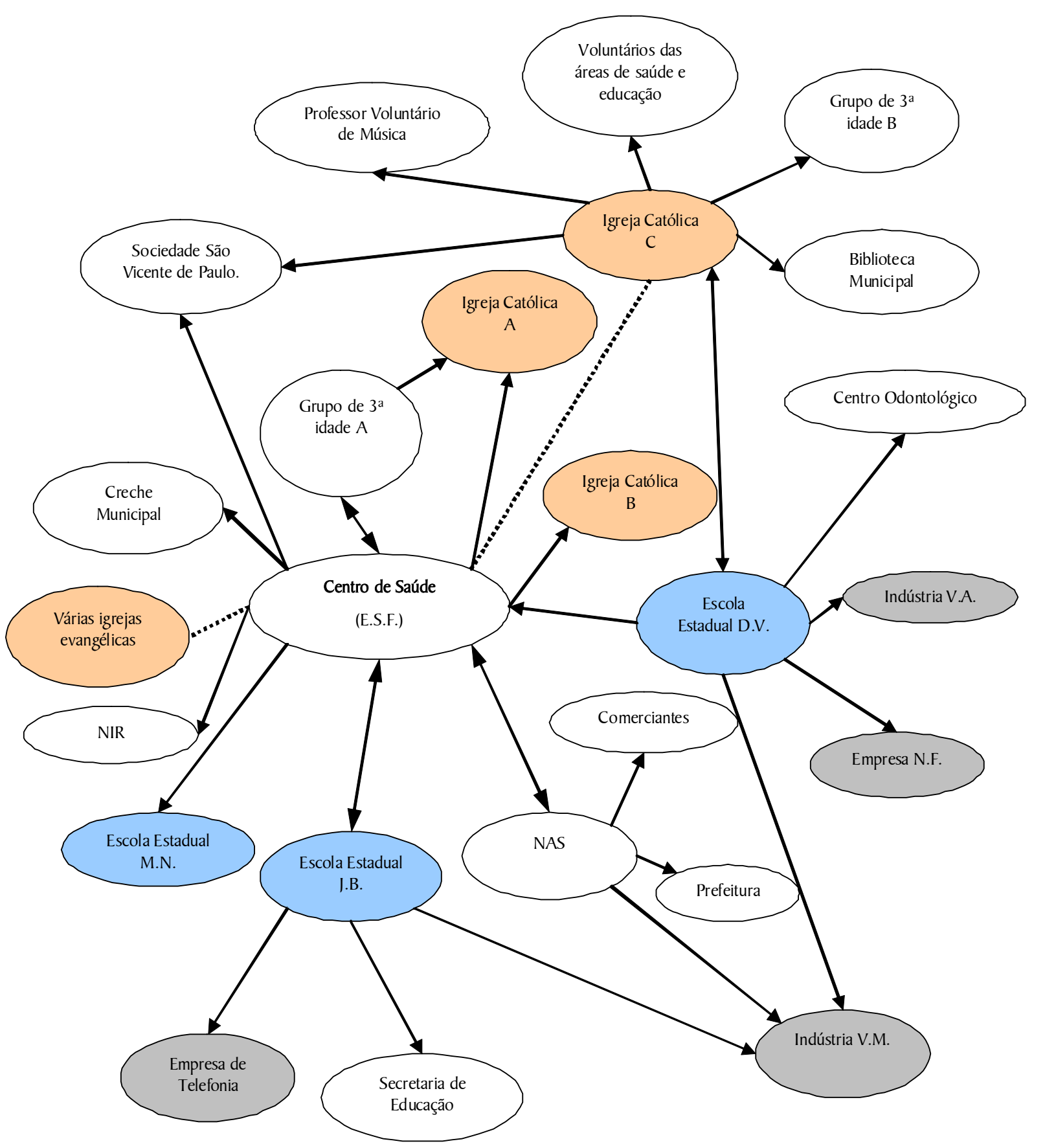

Figura I. Parcerias estabelecidas no território da ESF. Belo Horizonte, 2008. 
Nota-se Que, no cenário do estudo, existem diferentes equipamentos sociais e projetos importantes para promover a Qualidade de vida da população. Mas, de modo geral, a rede identificada não tem se articulado intersetorialmente, caracterizando-se, portanto, como uma rede multisetorial. Esta constatação fundamenta-se no fato de Que a maioria das ações e serviços prestados são planejados por um único setor ou equipamento social para serem aplicadas junto a outros. No processo de planejamento e aplicação não tem sido feito uma discussão horizontal acerca do Que cada um tem a contribuir. Essa realidade pode ser percebida mais claramente nos projetos Que as indústrias desenvolvem nas escolas, pois as atividades são idealizadas e operacionalizadas sem a participação dos representantes da educação. No Que se refere à Estratégia Saúde da Família, as entrevistas demonstram Que os representantes do Centro de Saúde desconhecem a existência de equipamentos sociais Que atuam junto à comunidade, desenvolvendo projetos destinados à promoção da saúde. Essa evidência remete a fragilidade ou inexistência de vínculo entre as equipes que atuam na atenção primária e os equipamentos sociais, o Que por sua vez inviabiliza a aplicação da intersetorialidade.

A intersetorialidade no contexto da Estratégia Saúde da Família

Os discursos dos sujeitos participantes deste estudo demonstram o tipo de relação que a ESF tem estabelecido com outros setores, serviços e equipamentos sociais. Nota-se Que existem algumas iniciativas, em prol da criação de parcerias intersetoriais, destinadas a melhorar a resolutividade dos problemas vividos pela população. Entretanto, as experiências identificadas são pontuais, esporádicas e desprovidas de um planejamento sistemático.

Dentre as experiências encontradas neste estudo, as mais significativas foram as Que se referem à parceria Centro de Saúde educação, sendo Que a escola mais próxima ao Centro de Saúde é a Que compartilha de uma parceria mais sólida. A escola é um cenário importante para a promoção da saúde porQue nela alunos, pais, professores e demais profissionais da educação permanecem e convivem. Em resumo, a ampliação do impacto das ações de promoção da saúde nas escolas precisa apoiar-se na soma das contribuições dos setores saúde e educação e não no repasse de parte da execução das tarefas de um setor para outro ${ }^{(8)}$.

A partir das falas dos participantes da pesquisa foi possível perceber que a relação do Centro de Saúde com equipamentos sociais englobam principalmente as seguintes práticas: encaminhamento de usuários para consulta; promoção de palestras de educação preventiva; assistência emergencial às carências nutricionais.

Tanto os discursos Quanto as observações em campo evidenciam Que a relação do Centro de Saúde com seus parceiros é, essencialmente, de prestação de serviços de caráter assistencialcurativista ou, no máximo, preventivista. Nota-se Que as práticas de promoção da saúde são incipientes e Que existe um limite no Que se refere ao reconhecimento do potencial da ESF para intervir nos determinantes sociais do processo saúde-doença.

Cabe ressaltar Que o informante do Centro de Saúde desconhece a existência de equipamentos sociais, em sua área de abrangência, relacionados a esporte e lazer, meio ambiente, trabalho e renda. Essa informação evidencia Que a ESF não tem utilizado todo o potencial da intersetorialidade para promover a saúde da população, haja vista a fragilidade ou inexistência de parcerias importantes no processo de enfrentamento dos determinantes da saúde. Essas constatações apontam para o distanciamento existente entre a prática e um dos pressupostos da atenção básica no SUS-BH Que diz respeito à intersetorialidade.

Esse achado reforça as considerações de Costa et $\mathrm{a}^{(9)}$ ao aforimar Que um dos desafios da Estratégia de Saúde da Família na reorientação do modelo assistencial refere-se à confusão conceitual sobre intersetorialidade, pois esta é tomada como responsabilidade individualizada a partir das demandas individualizadas dos usuários. Desta forma, se identifica a intersetorialidade como um processo de trabalho penoso e solitário. Entende-se, ainda, a necessidade da criação de uma rede de apoio para a efetivação desse princípio e acredita-se que é preciso começar a entender e escutar a opinião de outros profissionais e setores para Que o trabalho seja de fato precursor de processos de mudanças no modelo assistencial.

\section{O impacto das concepções dos profissionais no processo de construção da prática intersetorial.}

A formação dos profissionais e, conseqüentemente, suas concepções são colocadas, pelos participantes do estudo, como fatores Que influenciam e/ou determinam as formas de intervenções em problemas vividos por indivíduos ou coletivos.

A análise dos discursos permite captar Que, para praticar a intersetorialidade, os profissionais, cuja área de atuação relacionase aos contextos de vida e saúde das pessoas, precisam ser capazes de perceberem tanto os limites setoriais Quanto os benefícios das ações integradas. Essa percepção é colocada como um fator facilitador no processo de construção da intersetorialidade, visto Que impulsiona a busca por parcerias Que, por sua vez, permitem dar respostas mais efetivas e inovadoras aos complexos problemas sociais.

No Que se refere especificamente ao setor saúde, é evidenciado Que as concepções de saúde e doença dos profissionais influenciam suas práticas. Se o profissional orienta-se pelo paradigma biologicista, a medicalização será a principal forma de atuação. Entretanto, se ele incorpora o paradigma da produção social da saúde, o mesmo entende Que o processo saúde-doença é influenciado por múltiplos fatores Que extrapolam o setor saúde, cabendo então, além da Clínica, um trabalho intersetorial.

Assim, a ESF, como estruturante da atenção básica, traz aos trabalhadores de saúde o desafio de rever suas praticas diante do paradigma de produção social da saúde. Torna-se fundamental investir na formação de profissionais capacitados para lidar com esse objeto ampliado, para aprimorar os instrumentos de trabalho em saúde e buscar a intersetorialidade ${ }^{(10)}$.

Sobre o profissional enfermeiro, os participantes do estudo o reconhecem como uma "figura chave", embora esclareçam Que seu potencial como articulador intersetorial encontra-se limitada pelo excesso de atividades dentro do Centro de Saúde. A referida limitação remete aos seguintes Questionamentos: A grande demanda da população por consultas e outros atendimentos intramuros do Centro de Saúde poderiam estar relacionados à falta de ações destinadas à prevenção de agravos e promoção da saúde? Qual o valor e prioridade Que a prevenção e promoção têm no planejamento da assistência prestada pela atenção básica?

Chiesa $^{(10)}$ contribui com essa discussão ao colocar Que a ESF 
propõe ao enfermeiro um trabalho Que contemple a dupla dimensão individual/ coletivo do processo saúde- doença, resgatando a possibilidade de uma atuação ampliada e específica, no sentido da execução de ações cuja lógica central seja a necessidade de saúde do usuário. O campo de promoção da saúde reitera essa dupla dimensão do trabalho da enfermeira (individual/ coletivo) e propõe a articulação intersetorial como uma habilidade necessária para o enfrentamento dos problemas de saúde da população(II).

Inojosa ${ }^{(12)}$ corrobora com essa análise ao expor Que dentre as dificuldades para a intersetorialidade, existe aquela relacionada à sobrecarga de responsabilidades dentro da política setorial, a Qual impede os profissionais de olharem além do objeto específico de atuação.

Identificam-se, nos discursos dos participantes da pesquisa, relatos Que apontam para a importante influência de conhecimentos em Ciências Sociais na formação acadêmica dos profissionais. Cabe ressaltar Que a experiência vivenciada, durante a coleta dos dados em campo, também permitiu perceber Que os sujeitos Que têm uma formação em Ciências Sociais ou Que não são graduados, mas participam de discussões relacionadas a este campo de conhecimento, demonstram maior facilidade de entender e apoiar a intersetorialidade.

Além de conhecimentos em ciências sociais, também é evidenciada a necessidade de Que haja uma formação mais humanista, de profissionais engajados, sensíveis às situações de vulnerabilidade e Que tenham responsabilidade social. Essa compreensão vai ao encontro das proposições feitas por Wimmer e Figueiredo ${ }^{(6)}$, ao afirmarem Que, além da capacidade científica, do domínio técnico e da ação política, os profissionais Que atuam na saúde precisam ter compromisso com o desenvolvimento da comunidade fundamentado em certas atitudes como: amor, escuta, afetividade, respeito, tolerância, abertura ao novo e à justiça.

Sugere-se Que os processos de seleção de profissionais para atuação na atenção básica incluam avaliações Que permitam selecionar trabalhadores com perfil condizente com os princípios do SUS e com os objetivos da ESF. Além disso, é de suma importância, Que as universidades comprometam-se em formar profissionais Que tenham princípios de cidadania e compromisso social.

Da fragmentação à integração: rompendo o limite do olhar setorial em busca da construção de um espaço comunicativo Que possibilite a resolução de problemas complexos.

Os participantes da pesQuisa discorrem sobre a estrutura organizacional setorializada presente em nossa sociedade e apontam a comunicação como elemento fundamental à operacionalização da pratica intersetorial. Nota-se Que a saúde é colocada como uma política Que alcançou avanços no Que se refere à atenção integral, porém possui limitações para praticar a universalidade com equidade.

Essa proposição aponta para a possibilidade de o setor saúde ser um estimulador da construção da intersetorialidade, visto Que tem como um de seus princípios a integralidade Que, por sua vez, necessita da articulação de saberes, setores e seguimentos sociais para ser alcançada.

Em se tratando da limitação em praticar a universalidade com equidade, na perspectiva da ação intersetorial, a população exposta a maior vulnerabilidade sócio-econômica tem necessidade ampliada de ter acesso a ações e serviços Que operem sobre os determinantes e condicionantes do processo saúde-adoecimento. Assim, praticar universalidade sem negligenciar a equidade implica em colocar a disposição de todos os usuários do SUS ações de promoção da saúde, intensificando esta prática no contexto dos grupos populacionais mais vitimados por inieüidades sociais, o Que demanda maior articulação. Essa análise vai ao encontro da proposta do Programa BH Cidadania Que busca promover a inclusão social da população vulnerabilizada, através da acessibilidade aos bens e serviços públicos. O referido programa, criado em Belo Horizonte no ano de 2002, busca implementar um modelo de gestão baseado na descentralização, articulação e integração intersetorial, priorizando as áreas de maior vulnerabilidade social(13).

Os relatos dos participantes demonstram, também, Que a educação tem limitado sua atuação a ministrar o conteúdo educacional curricular e apresenta dificuldades de desenvolver atividades mais amplas, de promoção da Qualidade de vida dos educandos.

Nobre ${ }^{(14)}$, ao refletir sobre o papel do setor saúde e os desafios da prática intersetorial a partir da experiência no Programa de Prevenção e Erradicação do Trabalho Infantil do Estado da Bahia, destaca a baixa adesão do sistema formal de ensino ao programa. Em contrapartida, as duas escolas Que participaram do presente estudo compartilham de várias experiências de parcerias Que possibilitam a promoção da saúde biopsicosocial dos estudantes. Ante a essa contradição, deve-se Questionar se o exemplo das duas escolas é uma exceção dentro do sistema educacional ou se as experiências inovadoras do setor educação não estão sendo divulgadas.

A assistência social é apontada como uma política dotada de maior facilidade para trabalhar com a intersetorialidade, devido ao seu objeto de estudo estar relacionado às Questões sociais em toda a sua complexidade.

Os discursos demonstram, ainda, Que a falta de consenso entre os setores saúde, educação e assistência social são entraves Que se opõem ao desenvolvimento das ações intersetoriais. Ckagnazaraff, Melo e Carvalho ${ }^{(15)}$, ao analisarem a gestão intersetorial no Programa BH Cidadania, corroboram essa discussão ao afirmarem Que a falta de consenso acerca do papel a ser cumprido pelos diferentes funcionários e a incerteza sobre em Que consiste o trabalho intersetorial são fatores Que dificultam a operacionalização da intersetorialidade. Os mesmos autores expressam que deve haver também um nivelamento de conceitos, Que são bastante variados, gerando problemas na compreensão do papel e da função dos funcionários ${ }^{(15)}$.

É evidenciado, através dos discursos dos participantes, Que a comunicação entre os vários setores e segmentos sociais é essencial para vencer a fragmentação setorial e dar respostas mais efetivas aos complexos problemas existentes em nossa sociedade. As relações de poder existentes entre os diferentes campos de conhecimentos e políticas também se apresentam como desafios a serem superados para se alcançar o diálogo intersetorial.

Os achados remetem à necessidade de ampliação da discussão sobre a prática intersetorial para Que a proposta de articulação em rede de parcerias seja compreendida e para Que, a partir de então, sejam criadas estratégias Que viabilizem sua aplicação. De antemão é explicitada a necessidade da criação e ampliação de espaços 
comunicativos, nos Quais os diferentes setores, serviços e equipamentos sociais possam dialogar, no sentido de construir consensos, bem como identificar problemas e objetivos comuns para, então, planejar intervenções mais efetivas.

\section{Desvendando caminhos para praticar a nova e promissora estratégia intersetorial}

O presente estudo revela Que a intersetorialidade é uma estratégia em construção, da Qual os diferentes atores, setores e segmentos sociais ainda estão se apropriando. É evidenciado, através dos discursos, Que alguns atores sociais são capazes de perceber a complexidade de certos problemas enfrentados pela população e, por conseguinte, compreendem a necessidade de intervenções de caráter intersetorial. Essa percepção das limitações do olhar setorial é o primeiro passo para se alcançar a articulação intersetorial, visto Que essa nova maneira de trabalhar baseia-se no reconhecimento da necessidade de criar novas alternativas de intervenção Que dependem da articulação de outros olhares, saberes e forças. Entretanto, existe uma limitação no Que se refere à operacionalização da intersetorialidade. Em suma, os sujeitos que atuam nos distintos órgãos e instituições sociais reconhecem a demanda por ações intersetoriais, mas ainda não sabem como praticá-la.

Os discursos revelam que têm prevalecido entre as políticas sociais relações de disputa de poder; bem como de transferência de problemas e responsabilidades. Mas, há entre os participantes o entendimento de Que para Que a intersetorialidade efetivamente seja praticada, é mister Que sejam construídas relações de compartilhamento de responsabilidades, poderes e saberes. Os participantes assinalam, ainda, Que a construção da intersetorialidade corresponde a um processo complexo Que requer paciência, visto Que demanda transformações nos modos de pensar e agir historicamente estabelecidos. Neste contexto amplo e complexo de construção, o início do diálogo intersetorial é reconhecido como um importante avanço. Também é explicitado Que, enquanto processo gradual, a intersetorialidade encontra-se na fase de construção coletiva de novos conceitos e novas metodologias Que viabilizem sua aplicação.

Rocha ${ }^{(13)}$ expõe Que processos de mudança não são imediatos, não ocorrem em curto espaço de tempo. O caminho em direção a intersetorialidade corresponde a um processo progressivo de construção de valores, atitudes, comportamentos, mecanismos e instrumentos, através dos Quais é solidificado o modelo proposto.

As constatações que emergiram dos discursos aqui analisados demonstram Que os caminhos da prática intersetorial ainda estão sendo desvendados. Essa proposição remete à necessidade de Que esforços sejam somados continuamente, no intuito de superar os desafios e incertezas que se opõem a essa nova proposta de trabalho.

\section{CONSIDERAÇÕES FINAIS}

O paradigma da produção social da doença e o conceito de saúde como Qualidade de vida, deram origem ao desafio de se construir novas possibilidades de trabalho para responder às necessidades de saúde da população. Enquanto estratégia destinada a reorientar o modelo assistência, através da prestação de uma assistência pautada nos princípios da universalidade, equidade, integralidade e participação social, a Estratégia Saúde da Família configura-se como espaço privilegiado para o desenvolvimento de práticas promotoras de saúde. Sendo assim, discutir sobre as ações intersetoriais para promoção da saúde no contexto da ESF, constituiu objeto de estudo necessário na identificação dos desafios e das possibilidades existentes no processo de trabalho da atenção básica.

Apreendeu-se com os resultados da pesquisa Que, de modo geral, existe um consenso acerca da necessidade e importância da intersetorialidade para responder aos problemas enfrentados pela população. Entretanto, na prática, percebe-se Que a intersetorialidade ainda é um objetivo a ser alcançado.

Fica evidenciado Que, dentro de um território, existem várias possibilidades de articulação em rede, mas, para Que o serviço de saúde local possa efetivamente construir parcerias intersetoriais é necessário ir além da negociação de tarefas e da transferência de responsabilidades. É essencial construir espaços comunicativos Que permitam a definição de conceitos e objetivos comuns viabilizando, assim, o planejamento participativo das ações Que demandam contribuições de outras entidades.

É enfática a referência à necessidade de comunicação entre os diferentes setores, serviços e equipamentos sociais. Nesse sentido, explicita-se a complexidades da operacionalização da intersetorialidade, pois sua aplicação implica a superação das hierarQuias institucionais e das relações de poder existentes entre as corporações profissionais, setores, políticas e segmentos sociais.

Ressalta-se Que as concepções dos profissionais das diversas áreas do conhecimento influenciam suas práticas podendo contribuir ou não com a mudança do modelo hegemonicamente setorializado para o modelo de articulação intersetorial. Desse modo, um dos desafios para a intersetorialidade é a formação de profissionais Que sejam capazes de perceber a complexidade dos problemas manifestos na sociedade e, por conseguinte, Que reconheçam a necessidade de ações intersetoriais para intervir em tais problemas. Essa proposição aponta para o importante papel das universidades e evidencia Que o modelo de ensino deve ampliar sua abordagem de modo a contribuir com a formação de sujeitos críticos e reflexivos, com potencial para intervir na realidade social.

O presente estudo também permitiu compreender Que as ações intersetoriais em saúde são reconhecidas como uma nova proposta, da Qual os sujeitos envolvidos ainda estão se apropriando. Portanto, ainda há de se superar os desafios e incertezas Que se opõem ao novo, dentre os Quis destacam-se a definição de metodologias e meios Que viabilizem a prática intersetorial. Nesse processo, árduo e conflitante de construção da intersetorialidade, são considerados como avanços, o reconhecimento tanto das limitações setoriais, Quanto da necessidade de articulação entre os setores, políticas, entidades não-governamentais, organizações populares, iniciativa privada, etc.

Finalmente, embora a ESF seja um espaço privilegiado para o desenvolvimento de ações intersetoriais para a promoção da saúde, essas práticas ainda são pouco evidentes. Enquanto proposta inovadora em processo de construção, a intersetorialidade já alcançou alguns avanços, mas muitos desafios ainda estão sendo enfrentados para operacionalizar essa estratégia Que contraria interesses hegemônicos. 


\section{REFERÊNCIAS}

1. Finkelman J. Evolução das políticas e do sistema de saúde no Brasil. In: Finkelman, J. Caminhos da saúde pública no Brasil. Rio de Janeiro: Fiocruz; 2002. p. 237-95.

2. Buss PM. Promoção da Saúde e Qualidade de Vida. Ciên Saúde Coletiva 2002;5(1): 163-77.

3. Sousa MF. O Programa Saúde da Família no Brasil: análise do acesso à atenção básica. Rev Bras Enferm 2008; 6I (2): 153-8.

4. Ministério da Saúde (BR). Secretaria de Vigilância em Saúde. Política Nacional de Promoção da Saúde. Brasília: Ministério da Saúde; 2006.

5. Teixeira CF, Paim IS. Planejamento e Programação de Ações Intersetoriais para a Promoção da Saúde e da Qualidade de Vida. In: Teixeira CF, Paim IS, Villasboa AL. Promoção e Vigilância da Saúde. Salvador: Instituto de Saúde Coletiva; 2002. p. 59-78.

6. Wimmer GF, Figueiredo GO. Ação coletiva para Qualidade de vida: autonomia, transdisciplinaridade e intersetorialidade. Ciên Saúde Coletiva 2006; I I (1): 145-54.

7. Minayo MCS. Hermenêutica- Dialética como caminho do ensamento social. In: Minayo MCS, Deslandes SF, organizadores. Caminhos do Pensamento: epistemologia e método. Rio de Janeiro: Fiocruz; 2002. p. 83-107.

8. Ministério da Saúde (BR). Secretaria de Vigilância em Saúde. Saúde e Prevenção nas escolas: guia para a formação de profissionais de saúde e de educação. Brasília: Ministério da
Saúde; 2006.

9. Costa GD, Cotta RMM, Ferreira MLSM, Reis JR, Franceschini SCC. Saúde da família: desafios no processo de reorientação do modelo assistencial. Rev Bras Enferm 2009; 62(1): 1 13-8.

10. Chiesa AM. A Promoção da Saúde como eixo estruturante do trabalho de enfermagem no Programa de Saúde da Família. Nursing 2003; 64(6): 40-6.

1 1. Silva KL, Sena RR, Grillo MJC, Horta NC, Prado PMC. Educação em enfermagem e os desafios para a promoção da saúde. Rev Bras Enferm 2009; 62(1): 86-91.

12. Inojosa RM. Intersetorialidade e a configuração de um novo paradigma organizacional. RAP 1998; 32(2): 35-48.

13. Rocha MCG. Exclusão social e gestão local intersetorial: desafios do Programa BH Cidadania. In: X Congresso Internacional do CLAD sobre a Reforma do Estado e da Administração Pública, 2005 out 18-2 1; Santiago, Chile. Santiago: CLAD; 2005. p. $1-18$.

14. Nobre LCC. Trabalho de crianças e adolescentes: os desafios da intersetorialidade e o papel do Sistema Único de Saúde. Ciênc Saúde Coletiva 2003; 8(4): 963-71.

15. Ckagnazaroff IB, Melo ISC, Carvalho DN. Da gestão da intersetorialidade: o caso do Programa BH Cidadania, Brasil. In: $X$ Congresso Internacional do CLAD sobre a Reforma do Estado e da Administração Pública, 2005 out 18-2 I; Santiago, Chile. Santiago: CLAD; 2005. p. 1-14. 